Original Research Paper

\title{
Far-Red Spectrum of Second Emerson Effect: A Study Using Dual-Wavelength Pulse Amplitude Modulation Fluorometry
}

\author{
${ }^{1}$ V.S. Lysenko, ${ }^{1}$ T.V. Varduny, ${ }^{1}$ E.I. Simonovich, ${ }^{1}$ O.I. Chugueva, ${ }^{1}$ V.A. Chokheli, ${ }^{1}$ M.M. Sereda, ${ }^{1}$ S.N. \\ Gorbov, ${ }^{2}$ V.P. Krasnov, ${ }^{1}$ E.K. Tarasov, ${ }^{1}$ I.Y. Sherstneva and ${ }^{1}$ M. Yu Kozlova \\ ${ }^{1}$ Academy of Biology and Biotechnology, Southern Federal University, Rostov-on-Don, Russia \\ ${ }^{2}$ Rostov State Medical University, Rostov-on-Don, Russia
}

Article history

Received: 13-09-2014

Revised: $10-10-2014$

Accepted: 19-11-2014

Corresponding Author:

V.S. Lysenko,

Academy of Biology and

Biotechnology, Southern

Federal University, Rostov-on-

Don, Russia

Email: vs958@yandex.ru

\begin{abstract}
Non-additive enhancement of the photosynthesis excited by simultaneous illumination with far-red light and light of shorter wavelengths is called as "second Emerson effect". Its action spectra are well-known as a photosynthetic yield's dependence on light wavelength in red (630-690 nm) spectral region at a constant-wavelength far-red illumination near 700-715 nm. However, the opposite dependence of the photosynthetic yield's of shorter constant-wavelength light (red or blue) on light wavelength in far-red $(690-760 \mathrm{~nm})$ spectral region was never studied. In this study the action spectrum of second Emerson effect was studied using a fast-Fourier dual-wavelength Pulse Amplitude Modulation (PAM) fluorometry. Chlorophyll fluorescence in ailanthus (Ailanthus altissima Mill.) leaves was excited with blue modulated light. Far-red induced decrease of fluorescence (fluorescence shift-FRIFS) was studied in response to illumination of leaves with a background light from 690 to $760 \mathrm{~nm}(10 \mathrm{~nm}$ step $)$, calculating FRIFS $=\left(\mathrm{F}_{0}-\mathrm{Fs}\right) / \mathrm{F}_{0}$, where $\mathrm{F}_{0^{-}}$ fluorescence measured without and Fs-with far-red light. Maximum FRIFS was observed at $720 \mathrm{~nm}(11.8 \%)$, but it still remained considerable at $740,750 \mathrm{~nm}$ and a low FRIFS values were revealed at 690 and even at $760 \mathrm{~nm}$. Measurements carried out with blue saturating flashes during and after far-red illumination showed the increase of quantum yield of Photosystem II (PSII), calculated as Fv/Fm at $720 \mathrm{~nm}$ background light. FRIFS had lower values under excitation with red modulating light. It is concluded that FRIFS is a result of a photochemical quenching caused by an additional selective far-red excitation of PSI in conditions when PSII is preferably excited by blue light thus leading the PSI to limit non-cyclic electron flow. The contradiction between the known absorption spectra of PSI-light harvesting complex I and the observed action spectrum of second Emerson effect (FRIFS spectrum) is discussed.
\end{abstract}

Keywords: Second Emerson Effect, Far-Red Light, Fast-Fourier PAMFluorometry, Photosystem I, Photosysten II, Thylakoid Electron Transport, Ailanthus Altissima

\section{Introduction}

Red drop effect and second Emerson effect are related to the basic phenomenology of photosynthesis. In their pioneer research Emerson and Lewis (1943) studied action spectra of photosynthetic oxygen evolution in the green alga Chlorella pyrenoidosa and demonstrated that oxygen quantum yield began to decline rapidly from $680 \mathrm{~nm}$ of exciting light and completely eliminated near $700 \mathrm{~nm}$. This phenomenon was called by Emerson as "Red drop". 14 years later, Emerson, Chalmers and Cederstrand (Emerson et al., 1957) showed that the oxygen yield of photosynthesis in far-red region could be strongly increased by using the supplementary red light at $650 \mathrm{~nm}$. Thus, the quantum yield of $720 \mathrm{~nm}$ light applied alone achieves only approximately $50 \%$ from that at the simultaneous presence of 720 and $650 \mathrm{~nm}$ light. In other words the quantum yield of photosynthesis obtained by simultaneous illuminating with red and far-red light is 
higher than the sum of the quantum yields obtained by illuminating with separately applied light sources from these spectral regions. Now the non-additive enhancement of the photosynthesis excited by simultaneous illumination with far-red light and light of shorter wavelengths is known as a second Emerson effect. Currently it is well known that far-red light at wavelengths $>700 \mathrm{~nm}$ selectively excites Photosystem I (PSI), whereas the light at a shorter wavelengths drives both photosystems-PSI and PSII (Delosme, 2003; Joliot et al., 2006). When illuminating higher plants, far-red light (>700 nm, if applying alone) is able to excite Cyclic electron transport around PSI (CET-PSI) in C4-plants or excite PSI in C3 and C4 plants if this photosystem operates in series with PSII in the process of a non-cyclic electron transport: In the last case a supplementary light source in the spectral region of 440 to $680 \mathrm{~nm}$ is necessary.

Far-red light sources are widely used in photoacoustic studies of biochemical processes involving CET-PSI (Joliot et al., 2006; Hou and Sakmar, 2010). Besides, far-red light can be used in dualwavelength excitation experiments to test PSI and PSII coupling within a single linear electron transport chain (Lysenko, 2012). Thus we showed that only a Cyclic Electron Transport (CET-PSII or/and CET-PSI) occurs in the stomata cells thylakoids of albino leaf sectors of variegated Ficus benjamina plants under excitation by blue light whereas a non-cyclic electron transport is absent. Such a conclusion was based, among other facts, on the absence of any changes of chlorophyll fluorescence excited at $470 \mathrm{~nm}$ in response to the applying of the supplementary far-red light (Lysenko, 2012). In contrast, normal green tissues possessing a non-cyclic electron transport, show a clear increase of photochemical fluorescence quenching in this case, that was first discovered by Govindjee and Rabinowitch (1960) and confirmed in our work (Lysenko, 2012). The general assumption here is that the illumination of leaves with a far-red light drives PSI, which is coupled with PSII in a single electron transport chain and as a result, facilitates electron sink from PSII, that increases quantum yield of PSII and consequently increases photochemical fluorescence quenching (Govindjee and Rabinowitch, 1960; Lysenko, 2012).

Despite the above mentioned findings related to far-red light, the PSI action spectra of higher plants in far-red region is still unknown whether it could be obtained from photoacoustics or from dualwavelength excitation experiments. At that time the conventional wavelength of far-red light used in such studies usually ranged from 695 to $710 \mathrm{~nm}$ (Joët et al., 2002; Herbert et al., 1990; Malkin and Canaani, 1994). Among a few exceptions, Schreiber et al. (1997) described a successful use of $730 \mathrm{~nm}$ LEDs build in PAM-spectrometer for selective excitation of
PSI. Nevertheless, exploration with the 695-710 nm region seems to be rather a tradition, devolved from the pioneer studies on PSI or arising out of the conviction that the photosynthetic long-wave action spectra, as well as action spectra of photosynthesisrelated effects, couldn't be extended beyond the absorption spectra of antennae complexes. Indeed, the above mentioned Emerson's work (Emerson et al., 1957), describing a significant level of photosynthesis at $718 \mathrm{~nm}$, could not be easily explained since even the absorption spectrum (at a room temperature) of the most long-wave photosynthetic component of the thylakoid membrane-supercomplex of the LightHarvesting antennae of photosystem I (LHC I) and PSI core complex-does not extend beyond the $720 \mathrm{~nm}$ limit, where being within $1-2 \%$ of the absorbance at the peak maximum (Oort et al., 2008).

In the present work using a dual-wavelength pulse amplitude modulation fluorometry we show that the photosynthetic activity of far-red light (measured as a level of a second Emerson effect) still remains significant at $740,750 \mathrm{~nm}$ and a trace photosynthetic effects can be revealed even for $760 \mathrm{~nm}$ light.

\section{Objects and Methods}

\section{Plant Material}

Fully developed sun leaves were taken from 10-to 15-year-old trees of ailanthus (Ailanthus altissima (Mill.); tree of heaven) at the Botanical Garden of the Southern Federal University (Rostov-on-Don). The opting for the sun leaves was due to their more highamplitude fluorescence kinetics (Lichtenthaler et al., 2007; Lysenko et al., 2014).

All of the studied trees grew in the same soil, relief, water and lighting conditions. Throughout the entire period of the experiment ( 5 sunny days) all the leaves at the time of cutting (10.00-10.30) received PPFD approximately $1700 \mu \mathrm{mol}$ photons $\mathrm{m}^{-2} \mathrm{~s}^{-1}$. The leaves were used in the experiment no later than 10 minutes after detaching.

\section{Fast Fourier, Dual-Wavelength Pulse Amplitude Modulation (PAM) Fluorometry}

The measurements of chlorophyll fluorescence kinetics was performed in accordance with the generally accepted method of PAM fluorometry which involves excitation of fluorescence in the sample with a low intensity amplitude-modulating light (measuring light), whereupon the excited amplitude-modulated fluorescence $\left(\mathrm{F}_{0}\right.$, if the other light sources are not applied) is detected and the output signal is amplified at a selected frequency. In accordance with the conventional procedure (Schreiber, 2004) we evaluated 
the quantum yield of photosystem II as (Fm-F0)/Fm or $\mathrm{Fm} / \mathrm{Fv}_{\mathrm{V}}$ where $\mathrm{Fv}$ is a variable fluorescence (Schreiber, 2004). PAM-fluorometry was used in our modification based on a real-time, fast-Fourier spectrometry to select the measured signal, instead of traditional usage of lock-in amplifier. An analogous modification was previously being applied to process the photoacoustic signals, that allows to use of extremely low measuring light at an acceptable level of signal-to-noise ratio (Matishov et al., 2010; Lysenko, 2012; Lysenko and Varduny, 2013). Besides saturating flashes, we also used far-red light pulses of moderate intensity to assess the resulting changes in the amplitude of the signal from $\mathrm{F}_{0}$ to the lower values $(\mathrm{Fs})$. The difference $\left(\mathrm{F}_{0}-\mathrm{Fs}\right)$ and far-red induced fluorescence shift $\left(\mathrm{FRIFS}=\left(\mathrm{F}_{0^{-}}\right.\right.$ $\mathrm{Fs}) / \mathrm{F}_{0}$ )-was calculated to evaluate action spectra of second Emerson effect in a far-red region. Quantum yield of photosystem II under far-red light was calculated as (Fm-Fs)/Fm.

The following light sources were applied at the adaxial leaf surface in the experiments:

- $\quad$ Modulated $(300 \mathrm{~Hz})$ blue light $(\lambda \max =470 \mathrm{~nm}$, $0.1 \mu \mathrm{mol}$ photons $\mathrm{m}^{-2} \mathrm{~s}^{-1}$ ) emitted by blue LED

- $\quad 100$-s far-red light pulses from with $\lambda \max$ from 690 to $760 \mathrm{~nm}$ with half-bandwidth of $3 \mathrm{~nm} \mathrm{(30}$ $\mu \mathrm{mol}$ photons $\mathrm{m}^{-2} \mathrm{~s}^{-1}$ ), obtained by the monochromator equipped with a $300 \mathrm{Wt}$ halogen lamp, focusing mirror-lens system and IR absorbing $(>1000 \mathrm{~nm})$ liquid filter

- $\quad$ Blue saturating 2-s flashes (5 Wt LED, $\lambda \max =$ $470 \mathrm{~nm}, 4000 \mu \mathrm{mol}$ photons $\mathrm{m}^{-2} \mathrm{~s}^{-1}$ )
Chlorophyll fluorescence was registered by a photodiode through an interference filter $690 \mathrm{~nm}$. The signal from the photodiode was passed through a lownoise amplifier and then to the PC sound card. Realtime signal data processing was carried out to perform Fast Fourier Transform (FFT) using the SpectraLab program package. The following settings were applied: FFT size, 131,072 samples; sampling rate, 96,000 Hz; sampling format, $16 \mathrm{bit}$; spectral line resolution, $0.73 \mathrm{~Hz}$. Peak amplitude at a specified frequency $(300 \mathrm{~Hz})$ was measured in $1 \mathrm{~s}$ intervals and the obtained values were saved to a log file.

Photon fluxes were adjusted with USB4000-FL spectrometer (Ocean Optics, USA).

\section{Results and Discussion}

Far-red light pulses at all studied wavelengths applied to the ailanthus leaves resulted in a statistically significant decrease of the base fluorescence level $\left(\mathrm{F}_{0}\right)$ excited by modulated blue light and, therefore, to a noticeable values of FRIFS, that is shown in the Fig. 1a for 720,740 and $760 \mathrm{~nm}$ wavelengths and in the Fig $1 \mathrm{~b}$ for $690 \mathrm{~nm}$. As shown in Fig. 2, FRIFS have a clear maximum at $720 \mathrm{~nm}$ (at least being measured at the studied wavelengths). A low decreasing of $F_{0}$ (low FRIFS) was detected at 690 $\mathrm{nm}$ where it is coexists with a positive sharp peak of fluorescence level in response to the far-red light switching on and a negative peak-to the far-red light switching off (Fig. 1b).

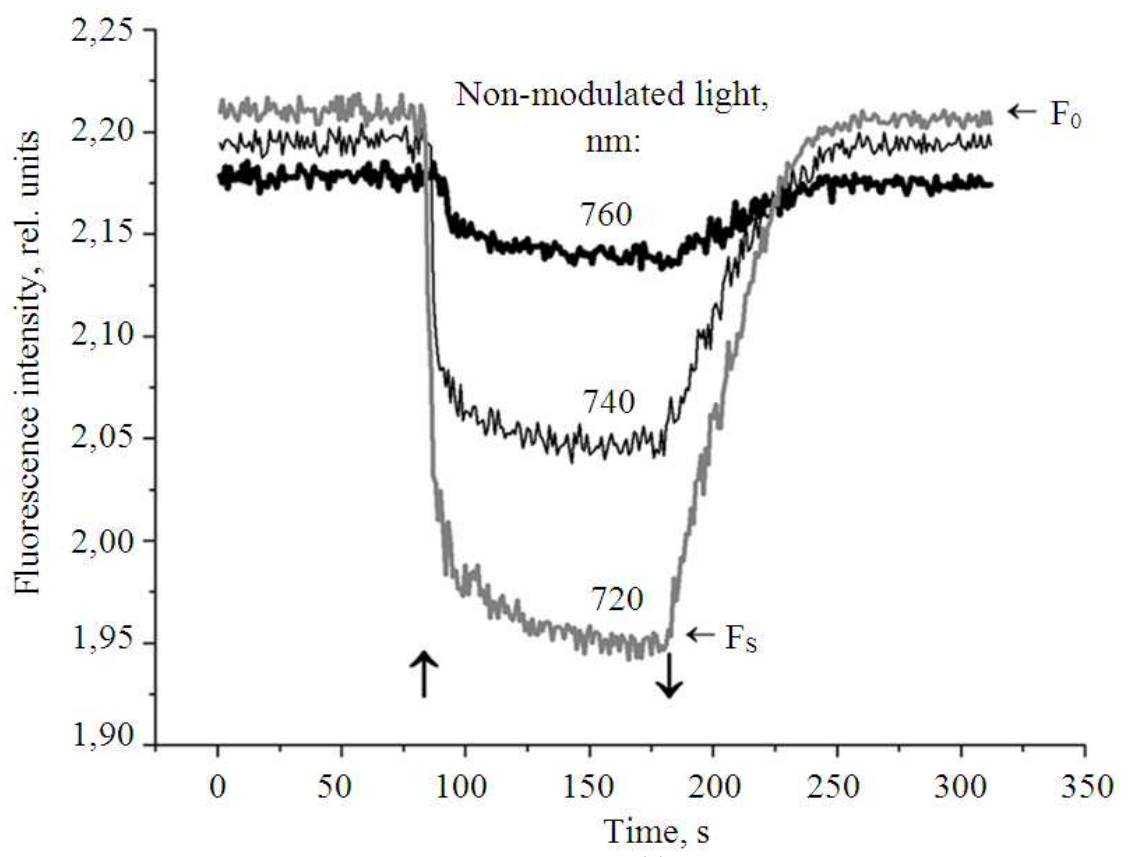

(a) 


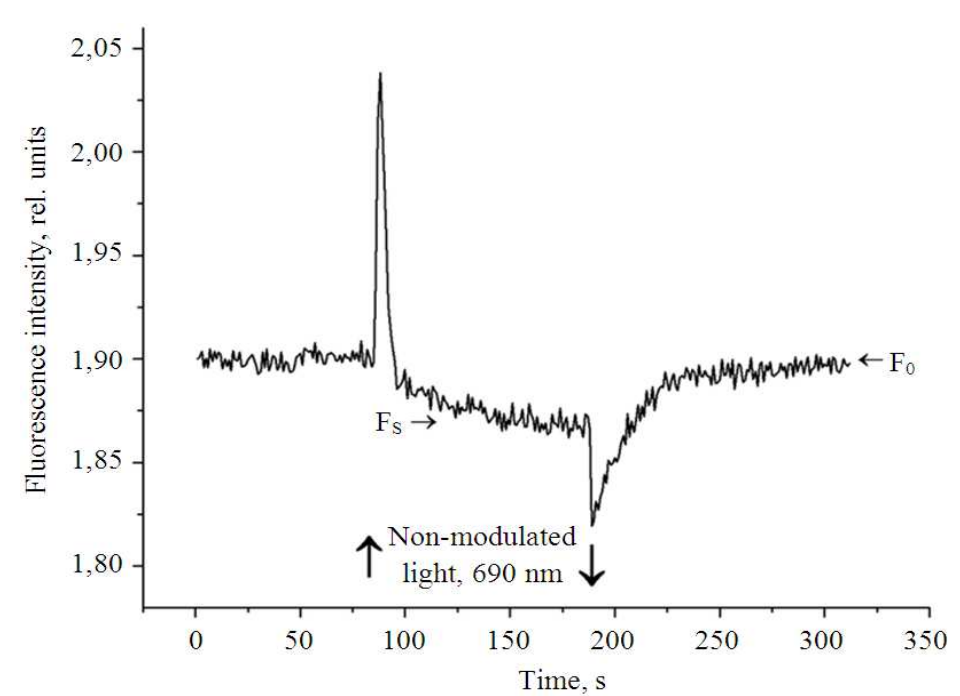

(b)

Fig. 1. Far-red induced fluorescence decrease (fluorescence shift-FRIFS) measured in Ailanthus altissima leaves at 720,740 and $760 \mathrm{~nm}$ as F0-Fs (A) and at $690 \mathrm{~nm}$ background light $\left(30 \mu \mathrm{mol}\right.$ photons $\left.\mathrm{m}^{-2} \mathrm{~s}^{-1}\right)(\mathrm{B})$. Typical curves. The fluorescence was excited by a weak $\left(0.1 \mu \mathrm{mol}\right.$ photons $\left.\mathrm{m}^{-2} \mathrm{~s}^{-1}\right)$ blue modulating light. F0 is a base level of fluorescence, Fs-fluorescence level decreased under background far-red illumination. $\uparrow \downarrow$-switching the non-modulated light on and off

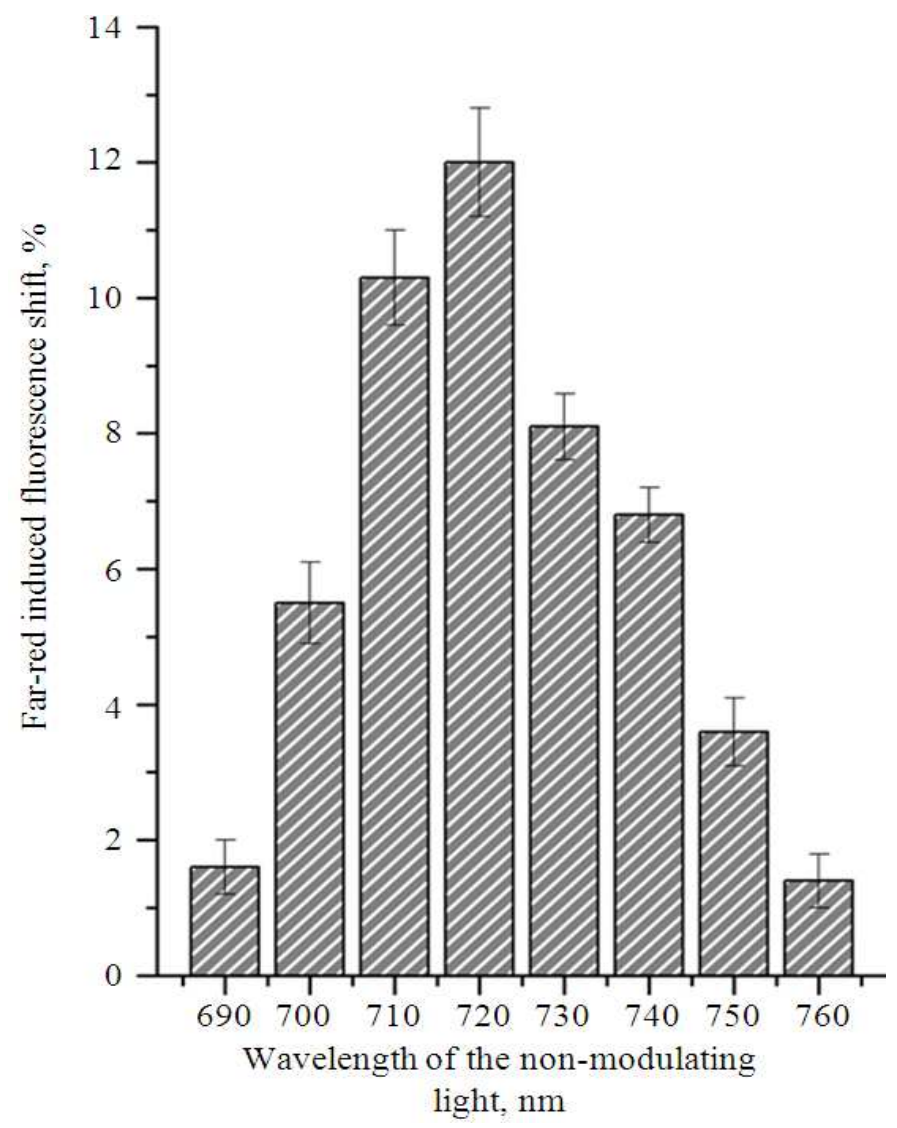

Fig. 2. Action spectrum of second Emerson effect measured as a far-red induced $690 \mathrm{~nm}$ Fluorescence Shift (FRIFS) in Ailanthus altissima leaves. The fluorescence was excited by weak $\left(0.1 \mu \mathrm{mol}\right.$ photons $\left.\mathrm{m}^{-2} \mathrm{~s}^{-1}\right)$ blue modulating light. Non-modulated far red light of moderate illuminance $\left(30 \mu \mathrm{mol}\right.$ photons $\left.\mathrm{m}^{-2} \mathrm{~s}^{-1}\right)$ was applied as 100 -s pulses (Fig. 1). Error bars $=\mathrm{SD} ; \mathrm{n}=10$. Spectrum's maximum value-FRIFS720 was significantly different from FRIFS 710 ( $\mathrm{p}<0.05$ ) and FRIFS730 $(\mathrm{p}<0.01)$ according to Student's t test 


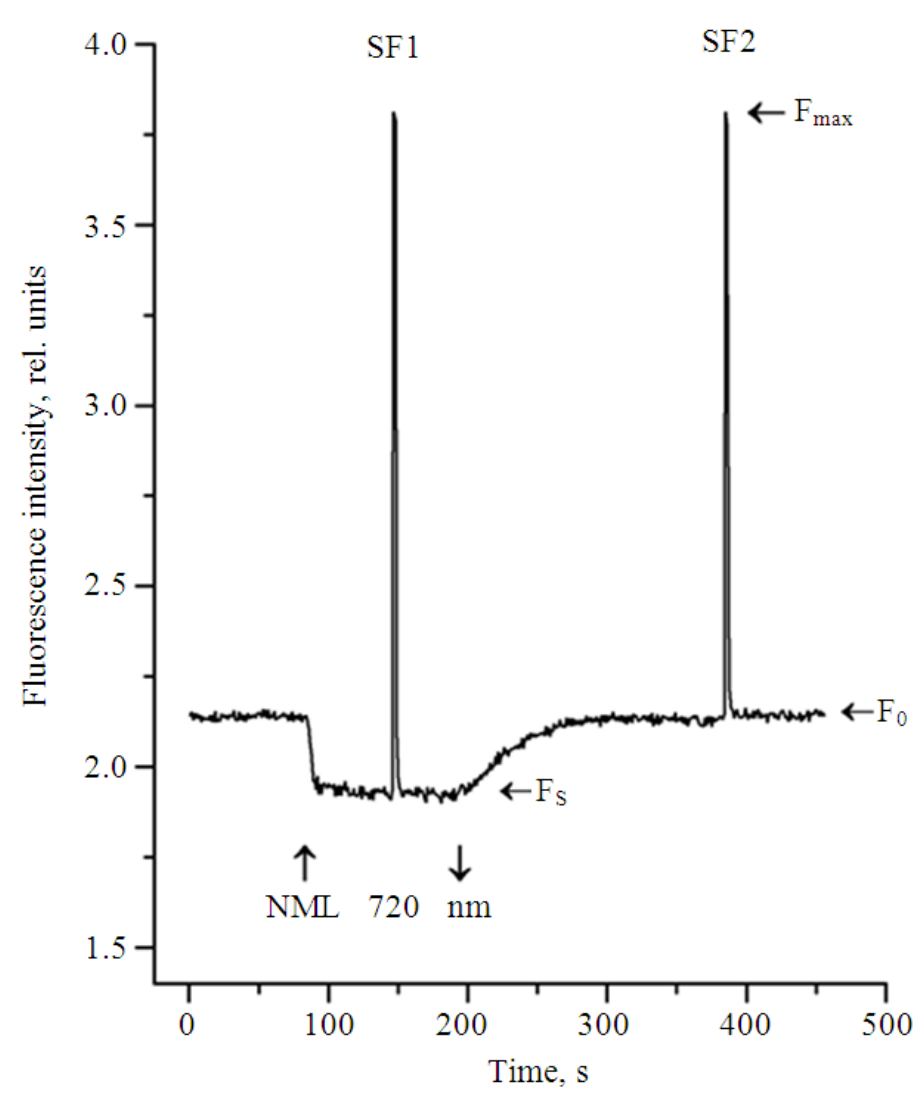

Fig. 3. Measurement of changes in quantum yield of PSII ( $\left.\Phi_{\text {PSII }}\right)$ caused by far-red illuminance (FRIFS). Quantum yield without applying the far-red light (saturating flash SF2): $\Phi_{\text {PSII }}=\left(\mathrm{F}_{\max }-\mathrm{F} 0\right) / \mathrm{F}_{\max }$. Quantum yield at the far-red light (saturating flash SF1): $\Phi_{\text {PSII }}^{\prime}=\left(\mathrm{F}_{\max }-\mathrm{F}_{\mathrm{S}}\right) / \mathrm{F}_{\max }$. Relative far-red induced increase of PSII quantum yield $\psi_{\mathrm{PSII}}=\left(\Phi_{\mathrm{PSII}^{-}}\right.$ $\left.\Phi_{\text {PSII }}\right) / \Phi_{\text {PSII }}=12.0 \pm 1.1 \%(\mathrm{X} \pm \mathrm{SD}, \mathrm{n}=10)$. NML-non-modulated far-red light at $720 \mathrm{~nm}\left(30 \mu \mathrm{mol}\right.$ photons $\left.\mathrm{m}^{-2} \mathrm{~s}^{-1}\right)$. The fluorescence was excited by weak blue modulating light $\left(\lambda \max =470 \mathrm{~nm}, 0.1 \mu \mathrm{mol}\right.$ photons $\left.\mathrm{m}^{-2} \mathrm{~s}^{-1}\right) .2-\mathrm{s}$ saturating flashes were applied at $470 \mathrm{~nm}, 4000 \mu \mathrm{mol}$ photons $\mathrm{m}^{-2} \mathrm{~s}^{-1}$ ). $\Phi_{\text {PSII }}$ and $\Phi_{\text {PSII }}^{\prime}$ were significantly different according to Student's t test $(\mathrm{p}<0.05)$.

Considering that the positive fluorescence kinetics (Kautsky effect) is characteristic of Photosystem II (PSII) only (Henriques, 2009), it can be concluded that the $690 \mathrm{~nm}$ light is capable to weak excitation of PSII in the given experimental conditions. The negative sharp peak could not be easily explained here, but this is the object of a separate research.

An unexpectedly high value of FRIFS was revealed at $740 \mathrm{~nm}\left(\right.$ FRIFS $\left._{740}\right)$ and a small FRIFS was registered even at $760 \mathrm{~nm}$. From the one hand, this data is in clear contradiction with the known absorption spectra of antennae complexes (as mentioned in the Introduction) (Oort et al., 2008; Jennings et al., 2004), from the other hand PSI-LHCI can be still excited at their long-wavelength absorbing tail of 710 to $740 \mathrm{~nm}$. It is unclear, however, why, for example, FRIFS $_{720}>$ FRIFS $_{700}$ or FRIFS $_{710}$, whereas PSI-LHCI absorption at 720 (as well as fluorescence excited by $720 \mathrm{~nm}$ light (Oort et al., 2008) is less then at 700 or $710 \mathrm{~nm}$. Considering this contradiction we couldn't exclude possibility of existing of some unknown components of intact PSI-LHCI complexes, which have longer wavelength characteristics, but which are lost or damaged in the process of separation of PSI-LHCI. It is an interesting fact in this connection that an initial fall of oxygen evolution at $680-700$ in sunflower leaves is replaced by an unexpected increase with a maximum at $750 \mathrm{~nm}$ so that a detectable $\mathrm{O}_{2}$ evolution is remained till $780 \mathrm{~nm}$ (Pettai et al., 2005).

The involvement of PSI in the FRIFS phenomenon as a factor limiting the non-cyclic electron transport is clearly confirmed by the fact, that in our experiments FRIFS has a lower value when the fluorescence was excited by red modulated light instead blue light (FRIFS $=2.5 \%$ under $640 \mathrm{~nm}$ light and $11.8 \%$ under $470 \mathrm{~nm}$ light-both at $0.1 \mu \mathrm{mol}$ photons $\mathrm{m}^{-2} \mathrm{~s}^{-1}$ ). It should be noticed here, that blue light at $470 \mathrm{~nm}$ preferentially excites PSII, whereas 620-640 nm light excites both photosystems nearly equally (Hogewoning et al., 2012). 
In the first case (blue light excitation) a higher limitation of non-cyclic electron transport is expected. In the second case (red light excitation), when both the photosystems are driven approximately equally, PSI weakly limits the total electron transport through the linear electron transport chain and, consequently, the additional selective excitation of PSI leads to a lower increase of PSII quantum yield resulting in a lower decrease of the fluorescence level.

FRIFS cannot be explained with any potentially possible processes of a far-red light induced nonphotochemical quenching so far as FRIFS is closely related to the increasing quantum yield of PSII, meaning that the far-red light excites PSI utilizing energy of $700-740 \mathrm{~nm}$ quanta in photochemical reactions. Thus the far-red light increases the Fv/Fm values by $12 \%$, when measured under saturating flashes during and after far-red illuminance (Fig. 3). Therefore FRIFS seems to be closely related with the photochemical quenching.

\section{Conclusion}

The data obtained supports the general idea that the specific far-red excitation of PSI can regulate the functioning of PSII (Shikanai, 2014) and demonstrates the FRIFS as a quantitative parameter reflecting the farred induced up-regulation of PSII in the case when the both photosystems are coupled in a single linear electron transport chain. Probably such a regulation is based on the stimulation of electron sink from PSII.

This study shows that the 715-740 nm spectral region is of a considerable interest to investigate in the field of photosynthetic light reactions in higher plants. Particularly, a perspective study can be undertaken to evaluate the action spectrum of PSI in the far-red region using photoacoustic methods, which are traditionally applied for the selective excitation of PSI only with 705-715 nm light whereas the longer wavelengths have not been studied.

In addition the results of our work suggest the potential possibility of usage the 730-nm LEDs for regulating photosynthesis in biotechnology of cultivated plants via selective PSI excitation. It is of interest considering recent studies (Yang et al., 2014; Olle and Viršile, 2013) devoted to the application of these LEDs under greenhouse conditions and considering that they are the most commercially available LEDs in the 700-750 $\mathrm{nm}$ far-red region.

\section{Acknowledgement}

The researchers are grateful to Southern Federal University (Rostov-on-Don) for the grant (N 213.01-07$2014 / 06$ PChVG) provided to achieve the aims of the present research. The project is performed with the equipment of Multiaccess Center "Biotechnology, Biomedicine and Environmental Monitoring", Multiaccess Center "High Technology", Laboratory of cellular and genomic technologies, Laboratory of plant physiology and ecology of Academy of Biology and Biotechnology of Southern Federal University.

\section{Funding Information}

The research was solely supported by a single grant from Southern Federal University (N 213.01-072014/06PChVG).

\section{Author's Contributions}

V.S.L. conceived the project, contributed in pulseamplitude fluorometry and wrote the paper; T.V. V., E.I.S. O.I.C., V.A.C., M.M.S., S.N.G., V.P.K., E.K.T., I.Y.S. and M.Yu.K. contributed in pulse-amplitude fluorometry.

\section{Ethics}

No part of manuscript reporting original work is being considered for publication in whole or in part elsewhere. The corresponding author affirms that all of the other authors have read and approved of the manuscript.

\section{References}

Delosme, R., 2003. On some aspects of photosynthesis revealed by photoacoustic studies: a critical evaluation. Photosynth. Res., 76: 289301. DOI: 10.1007/1-4020-3324-9_58

Emerson, R. and C.M. Lewis, 1943. The dependence of the quantum yield of Chlorella photosynthesis on wavelength of light. Am. J. Bot., 30: 165-178. DOI: $10.2307 / 2437236$

Emerson, R., R. Chalmers and C. Cederstrand, 1957. Some factors influencing the long-wave limit of photosynthesis. Proc. Natl. Acad. Sci. USA, 43: 133-143. DOI: 10.1073/pnas.43.1.133

Govindjee and E. Rabinowitch, 1960. Action spectrum of the "second Emerson effect". Biophys. J., 1: 73-89.

DOI: $10.1016 / \mathrm{S} 0006-3495(60) 86877-4$

Henriques, F.S., 2009. Leaf chlorophyll fluorescence: background and fundamentals for plant biologists. Bot. Rev., 75: 249-270. DOI: $10.1007 / \mathrm{s} 12229-009-9035-\mathrm{y}$

Herbert, S.K., D.C. Fork and S. Malkin, 1990. Photoacoustic measurements in vivo of energy storage by cyclic electron flow in algae and higher plants. Plant Physiol., 94: 926-934.

DOI: $10.1104 / p p .94 .3 .926$ 
Hogewoning, S.W., E. Wientjes, P. Douwstra, G. Trouwborst and W. Ieperen et al., 2012. Photosynthetic quantum yield dynamics: From Photosystems to Leaves. The Plant Cell, 24: 1921-1935. DOI: 10.1105/tpc.112.097972

Hou, H.J.M. and T.P. Sakmar, 2010. Methodology of pulsed photoacoustics and its application to probe photosystems and receptors. Sensors, 10: 56425667. DOI: $10.3390 / \mathrm{s} 100605642$

Jennings, R.C., G. Zucchelli, E. Engelmann and F.M. Garlaschi, 2004. The long-wavelength chlorophyll states of plant LHCI at room temperature: A comparison with PSI-LHCI. Biophys. J., 87: 488-497.

DOI: 10.1529/biophysj.103.038117

Joët, T., L. Cournac, G. Peltier and M. Havaux, 2002. Cyclic electron flow around photosystem I in C3 plants in vivo control by the redox state of chloroplasts and involvement of the NADHdehydrogenase complex. Plant Physiol., 128: 760769. DOI: $10.1104 / \mathrm{pp} .010775$

Lichtenthaler, H.K., K. Babani and G. Langsdorf, 2007. Chlorophyll fluorescence imaging of photosynthetic activity in sun and shade leaves of trees. Photosynth. Res., 93: 235-244.

DOI: $10.1007 / \mathrm{s} 11120-007-9174-0$

Lysenko, V. and T. Varduny, 2013. Anthocyanindependent anoxygenic photosynthesis in coloured flower petals. Sci. Reports.

DOI: $10.1038 /$ srep 03373

Lysenko, V., 2012. Fluorescence kinetic parameters and cyclic electron transport in guard cell chloroplasts of chlorophyll-deficient leaf tissues from variegated weeping fig (Ficus benjamina L.). Planta, 235: 1023-1033 DOI: $10.1007 / \mathrm{s} 00425-011-1560-3$

Lysenko, V.S., T.V. Varduny, P.O. Kosenko, Y.V. Kosenko and O.I. Chugueva et al., 2014. Video registration as a method for studying kinetic parameters of chlorophyll fluorescence in Ficus benjamina leaves. Russ. J. Plant Physiol., 61: 419425. DOI: 10.1134/S102144371403008X

Malkin, S. and O. Canaani, 1994. The use and characteristics of the photoacoustic method in the study of photosynthesis. Ann. Rev. Plant Physiol. Plant Mol. Biol., 45: 493-526.

DOI: 10.1146/annurev.pp.45.060194.002425
Matishov, G.G., V.S. Lysenko and V.G. Soier, 2010. Cyclic electron transport around photosystems I and II in thylacoids of light-green sectors of variegated Ficus benjamina L. leaves. Dokl. Biol. Sci., 435: 425-427. DOI: $10.1134 / \mathrm{S} 0012496610060153$

Oort, B., A. Amunts, J.W. Borst, A. Hoek and N. Nelson et al., 2008. Picosecond fluorescence of intact and dissolved PSI-LHCI crystals. Biophys. J., 95: 5851-5861.

DOI: 10.1529/biophysj.108.140467

Pettai, H., V. Oja, A. Freiberg and A. Laisk, 2005. The long-wavelength limit of plant photosynthesis. FEBS Lett., 579: 4017-4019. DOI: $10.1016 /$ j.febslet.2005.04.088

Schreiber, U., R. Gademann, P.J. Ralph and A.W.D. Larkum, 1997. Assessment of photosynthetic performance of prochloron in Lissoclinum patella in hospite by chlorophyll fluorescence measurements. Plant Cell Physiol., 38: 945-951. DOI: 10.1093/oxfordjournals.pcp.a029256

Shikanai, T., 2014. Central role of cyclic electron transport around photosystem I in the regulation of photosynthesis. Curr. Opin. Biotech., 26: 2530. DOI: 10.1016/j.copbio.2013.08.012

Yang, Z.Q., Y.X. Li, J.B. Zhang, J. Zhang and J. Zhu et al., 2014. Effects of the red: Far-red light ratio on photosynthetic characteristics of greenhouse cut Chrysanthemum. Hort. Sci., 40: 40-43.

Olle, M. and A. Viršile, 2013. The effects of lightemitting diode lighting on greenhouse plant growth and quality. Agric. Food Sci.

Joliot, P., A. Joliot and G. Johnson, 2006. Cyclic Electron Transfer Around Photosystem I. In: Advances in Photosynthesis and Respiration, Golbeck, J.H. (Ed.)., Springer, Dordrecht, Netherlands, ISBN-10: 978-1-4020-4255-3, pp: 639-656.

Schreiber, U., 2004. Pulse-Amplitude-Modulation (PAM) Fluorometry and Saturation Pulse Method: An Overview. In: Chlorophyll Fluorescence: A Signature of Photosynthesis, Papageorgiou G.C. and Govindjee, (Eds.)., Springer, Dordrecht, Netherlands, ISBN-13: 9781402032172 , pp: 279319. 